\title{
A prudent automated car ventilation system and driving data
}

\author{
Member \\ Non-member \\ Non-member \\ Non-member \\ Non-member
}

\author{
Hidemoto Nakagawa \\ Shinji Okazaki \\ Shukuji Asakura \\ Hideo Akimoto \\ Jun Kubo
}

\author{
(Yokohama National University) \\ (Yokohama National University) \\ (Yokohama National University) \\ (Advanoed Circuit Engineering Co. Ltd) \\ (Kubo Systems Inc.)
}

An automated car ventilation system (automatic damper), that avoids the intake of the exhaust fume of the foregoing vehicles almost completely, was developed. The system utilizes two gas sensors to detect the exhaust fume, one for gasoline cars and the other for diesel cars. It is well known that semiconductor gas sensors show certain response delay and contaminated air may be introduced during the delay period. The present system adopts the air reservoir to store the outside air temporally to compensate the response delay. It has been demonstrated that the present system effectively discarded the contaminated air, while it introduced clean and fresh outside air. Further the data on highways suggested that the level and type of the contamination varies widely with the number and type(gasoline or diesel, freight or passenger) of running cars, traffic conditions, geographical features, and wind.

Keyword: gas sensor, automatic damper, $\mathrm{NO}_{2}, \mathrm{CO}, \mathrm{HCs}$

\section{Introduction}

With the increasing awareness for the global conservations, regulations on automobile exhaust emission for an individual vehicle had been tightened. And at least in the advanced countries, including Japan, the pollutions due to car traffic in city areas are not worsening or slightly improving. However, as for NOx and SPM (suspended particulate matter), they cannot lower the contamination levels to their environmental standards in Japan. In several emerging countries where their priority is placed on their economic growth rather than environmental conservations, pollution level in traffic-congested area is far beyond the acceptance level of human beings. The pollution caused by heavy traffic is of major issue in both developed and emerging countries alike.

Kobe district court in Japan has made a noteworthy decision in January 2000. Local residents in the area sued the Hanshin Highway Public Corp. and the Japanese government to reduce the air pollution by the traffic and the court ordered the Public Co. and the government to reduce the emission. Apart from this decision, the Governor of Metropolitan Tokyo announced that he would regulate diesel cars in Tokyo to adopt SPM filters to reduce the emission starting in year 2003.

Needless to say, that the exhaust fume is unpleasant and harmful. This has been proved many times by the local residents of the heavily congested traffic area who suffered seriously by the asthma and other respiratory diseases. Further wealth of experimental data indicated that hydrocarbons (HCs) and SPMs, especially those from a diesel engine are cancer stimulating ${ }^{(2)}$. A driver on the road may suffer most seriously these effects from the exhaust of foregoing cars, although he is an assailant for the other drivers and local resident at the same time. His exposure time to polluted air may be short, but the temporal concentration could be more than several tens times than that of the local residents when the car sucks the direct exhaust fume from foregoing cars.

An automatic ventilation system (automatic damper) had been suggested ${ }^{(1,3,4)}$. A gas sensor monitors outside air and if polluted air is detected, the system shut down the ventilation damper to avoid the intake of the polluted air. An prototype of such system had been made ${ }^{(3)}$ to evaluate the effectiveness of the system and the driving data demonstrated that the system worked properly as originally aimed. But after the long term run, it was noticed that there were occasions when passengers notice the intake of the polluted air. The transient air intake, caused by the slow sensor response, could be the reason.

In this report, we modified the system to shut out the polluted air securely. Air qualities of outside and inside the cabin were monitored simultaneously to demonstrate the effectiveness of the system. Data collected on highway indicated that there were wide variations on the degree of pollution even if the traffic amounts were similar. Various factors that affect the level of pollution on roads were discussed based on the results accumulated on highways. 


\section{The ventilation system}

In the present system, $\mathrm{CO} / \mathrm{HC}$ (sensitive to $\mathrm{CO}$ and $\mathrm{HCs}$ ) and $\mathrm{NO}_{2}$ sensors were used to monitor outside air. Major toxic components in the exhaust of a gasoline engine were $\mathrm{CO}$ and $\mathrm{HCs}$, whereas those of a diesel engine contained $\mathrm{NO}_{2}{ }^{(2,3)}$. The $\mathrm{CO} / \mathrm{HC}$ sensor was $\mathrm{SnO}_{2}$ hot-wire type, supplied by New Cosmos Electric Co. Ltd. The $\mathrm{NO}_{2}$ sensor was $\mathrm{WO}_{3}$ semiconductor-type, supplied by Figaro Engineering Co. Ltd. The expected contamination levels of the harmful components on the roads are: $\sim 30 \mathrm{ppm}$ for $\mathrm{CO}$, $\sim 3 \mathrm{ppm}$ for $\mathrm{HCs}, \sim 2 \mathrm{ppm}$ for $\mathrm{NO}_{2}$. The requirements for these sensors as well as sensing characteristics of these devices were reported previously ${ }^{(3)}$. The $\mathrm{SnO}_{2}$ detector detects both $\mathrm{CO}$ and HCs. The sensitivity to $\mathrm{CO}$ was about $1 / 10$ of that to ethanol ${ }^{(3)}$. Since HCs contains several alcohol and other polar organics, it may be said that $\mathrm{CO} / \mathrm{HC}$ sensor detects both $\mathrm{CO}$ (the concentration of $\mathrm{CO}$ in the fume may be $\sim 10$ times higher than $\mathrm{HCs}$ ) and $\mathrm{HCs}$ evenly. Amplified signals of the transient responses to diesel exhaust were presented in Fig. 1. Baselines of the amplifier signals were shifted for the clarification purpose, but the increase in signal indicates the higher pollution levels for both signals. The engine was ignited for about $10 \mathrm{sec}$. The response of the $\mathrm{CO} / \mathrm{HC}$ sensor was relatively fast with a superficial rise time of less than $10 \mathrm{sec}$. and a fall time of about $10 \mathrm{sec}$. The response time of $\mathrm{NO}_{2}$ sensor was slower, with a superficial rise time of about $20 \mathrm{sec}$. The fall time was further slower, suggesting easy adsorption and slow desorption of $\mathrm{NO}_{2}$. The slow rise times of the sensor responses could be the cause of undesirable intake of the polluted air. In order to avoid this faulty intake, the system was modified to cope with the slow responses. An air reservoir to store outside air temporally was adopted. The capacity of the reservoir was about 20 liters.

Figure 2 shows the schematics of the present system. The

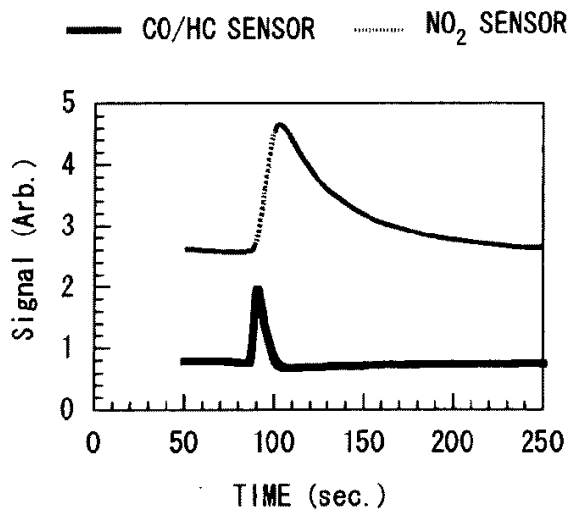

Fig. 1 Transient responses of sensors to exhaust fume

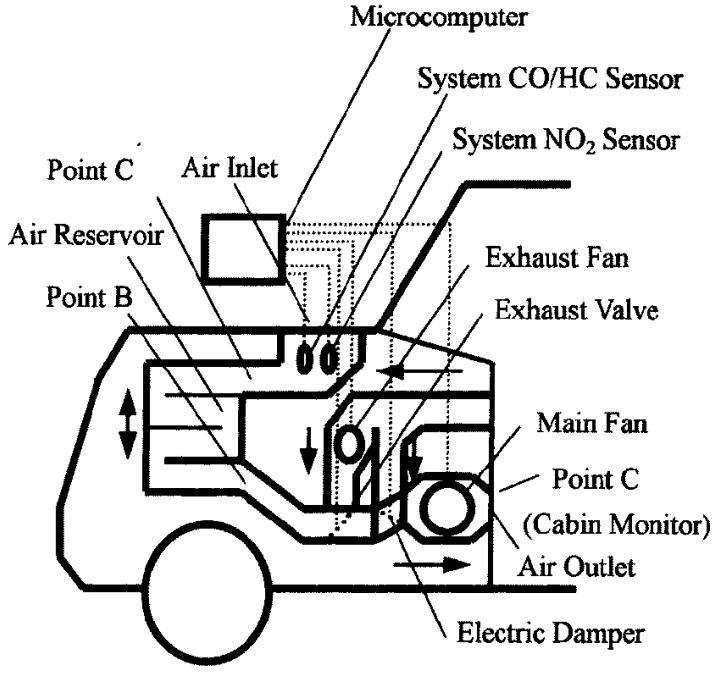

Fig. 2 System Schematics

system was installed in a sedan-type passenger car. Although the schematics are drawn as if it were placed within the engine room for the sake of clarity, major portion of the system including the bulky air reservoir was installed in the cabin under a dashboard. In this way, a commercially available car was easily modified. A shortcoming was that the reservoir had no direct access to evacuate polluted air except the air inlet, which necessitated us to add an extra procedure of discarding the polluted air when the air was polluted.

Operation of the system is as follows. System $\mathrm{NO}_{2}$ and $\mathrm{CO} / \mathrm{HC}$ sensors monitor the quality of outside air. When the outside air is judged to be clean, a damper is opened and a main fan is actuated, and outside air is introduced to cabin through an air reservoir. If the sensors detect polluted air, the system closes dumper and the main fan circulates the air inside the cabin. In this situation, the polluted air is kept within the reservoir. When the outside air becomes clean, the system opens an exhaust valve and evacuates the polluted air from the reservoir with an exhaust fan. After it evacuates the polluted air from the reservoir, the systcm opens the damper and starts intake of clean air. This evacuation procedure of the polluted air from the reservoir may be omitted if the system was designed to discard the polluted air from the reservoir to outside directly. In the present system, the reservoir was installed in the cabin space and the air inlet was the only access to discard the polluted air to outside. The main fan speed which was crucial for the system performance, since (the reservoir volume)/(air volume per unit time) determined the air delay time. The fan speed was controlled by the microcomputer and designed to be settable to two levels (low and high). In this report, the fan speed was 


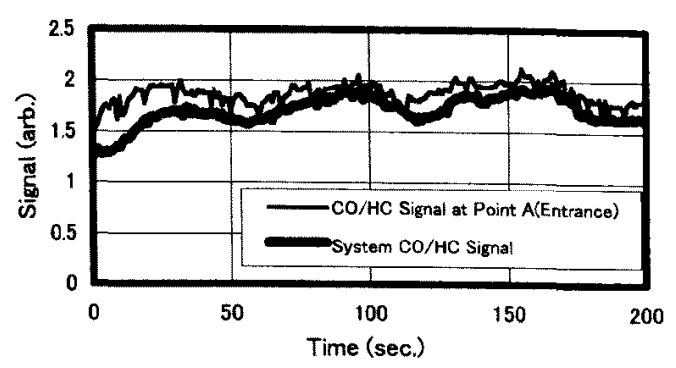

(a) Signals from point $\mathrm{A}$ and the system

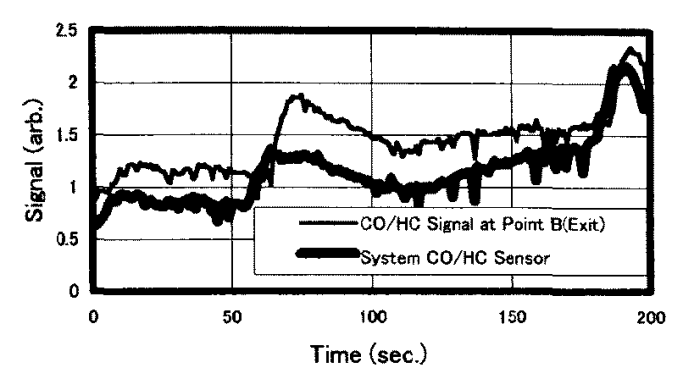

(b) Signals from point $B$ and the system

Fig. 3 Signal delay at the entrance(a) and exit(b) of the reservior.

\section{always adjusted to a low position.}

Since the sensitivities required in the present system were very high, the sensors especially $\mathrm{NO}_{2}$ sensor showed certain drift in time, or interference from humidity. Several algorithms had been suggested to eliminate these interferences ${ }^{(1,3,4,5)}$. The present system adopts the same method with the previous report ${ }^{(3)}$ : i.e. if a clean air signal last for 10 minutes, the system takes the lowest value within the period as the clean air baseline.

\section{System Performance}

Before collecting actual driving data, signals from $\mathrm{CO} / \mathrm{HC}$ sensor at the air inlet (system sensor), and that at the reservoir entrance (Point A in Fig. 2), and that at the reservoir exit (Point B in Fig. 2) were compared in order to investigate the effectiveness of the newly installed reservoir. Figure 3 (a) shows the $\mathrm{CO} / \mathrm{HC}$ signals at the reservoir entrance (Point A) and the outside (measured by the system sensors). Two signals were well correlated as expected, although the signals were somewhat noisy. The response of the system $\mathrm{CO} / \mathrm{HC}$ signal tended to be slightly behind the signal at the point $A$ (reservoir entrance), despite the fact that air goes through near the system sensor first and reaches at the reservoir entrance afterwards. This peculiar phenomenon may be attributed to a dust filter attached onto the system gas sensors. The system sensors were covered with polyester and glass wool filters to ensure long term operation under harsh environment. It might take few seconds for air to diffuse through this filter. The sensors at the reservoir entrance (Point A) or in the cabin (Point $\mathrm{C}$ ) were for monitoring purpose only, and temporally installed without any filters except mesh covers and no diffusion delay was expected. The signals at the air inlet and at the reservoir exit were compared in Fig. 3 (b). It is clear that the signal at the reservoir exit (Point B) was delayed from the signal at the outside (the system $\mathrm{CO} / \mathrm{HC}$ sensor). The delay time was about $10 \mathrm{sec}$. It is worth to mention that this value was longer than the superficial rise time of the $\mathrm{CO} / \mathrm{HC}$ sensor presented in Fig. 1, but shorter than that of the $\mathrm{NO}_{2}$ sensor.

\section{Results and Discussions}

Actual running data collected on the highway was presented in Figs. $4 \sim 6$.

Figure 4 presents the data collected near the university campus on a relatively congested highway with almost no wind. In order to investigate the effectiveness of the system, extra sensors of the same type used in the ventilation system were installed near the air outlet in the cabin (Point $\mathrm{C}$ ). Signals from these and from system sensors are presented in Fig. 4 (a). The origin of the ordinate for individual sensor was shifted for the comparison of trends with easy viewing. Although the ordinate was scaled with arbitrary units, one may crudely say that 4 division scale difference corresponds to order of $\sim 100 \mathrm{ppm} \mathrm{CO}$ or, of $\sim 10 \mathrm{ppm} \mathrm{HC}$ contaminations for the $\mathrm{CO} / \mathrm{HC}$ sensor. 2 division scale difference may corresponds to of the order of $\sim 10 \mathrm{ppm} \mathrm{NO}_{2}$ contamination for the $\mathrm{NO}_{2}$ sensor. The baselines of all the signals drifted from day to day, probably due to humidity. Fig. 4 (b) presents the result of a logical judgment by microcomputer for $\mathrm{CO} / \mathrm{HC}$ contamination. This logical signal is presented with a negative logic and the system judged the air to be dirty when this signal was 0 . Similarly Fig. 4 (c) presents the logic signal for the evacuation of the contaminated air from the reservoir, and Fig. 4 (d) presents the logic signal for the clean outside air intake: the system introduces outside air when this logic level is 0 .

When the $\mathrm{CO} / \mathrm{HC}$ system sensor detected polluted air (at $\sim 70$ sec.), the system closed the damper to stop the air intake and circulated the cabin air. The signal level of $\mathrm{CO} / \mathrm{HC}$ cabin monitor, more or less, stayed constant despite the sharp increase of the $\mathrm{CO} / \mathrm{HC}$ system sensor, which indicated the outside air pollution. Slight increase of the contamination level with the $\mathrm{CO} / \mathrm{HC}$ cabin monitor might be attributed to the leak of the electric damper and other components. It should be mentioned that the semiconductor gas sensors showed rather logarithmic response to the concentration and a response in the low concentration range tends to be expanded, whereas the response was compressed in high concentrations. When the $\mathrm{CO} / \mathrm{HC}$ system sensor found outside air 


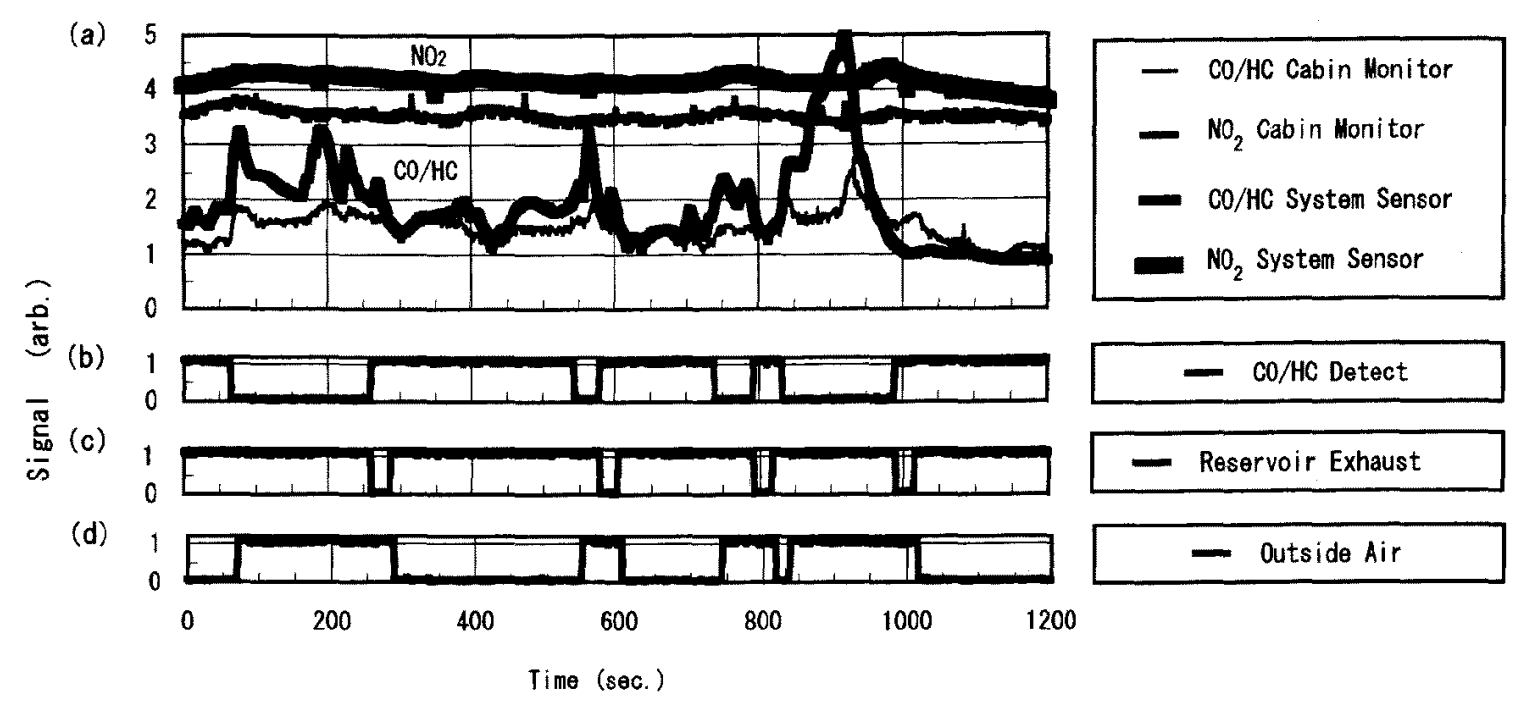

Fig. 4 Driving data on a crowded highway

had become clean $(\sim 260 \mathrm{sec})$, the system evacuated the polluted air stored within the reservoir first and then opened the damper to introduce outside air. Similar sequences were repeated at $550 \mathrm{sec}$. and at $740 \mathrm{sec}$. For the sequence at $740 \mathrm{sec}$, the test car was driving through Sengenshita Cross in Yokohama. This Cross situates at the footstep of steep hill. The annual average pollution level of NOx for this point once recorded to be the worst in Japan, probably because of heavy traffic and geographical features. For this time sequence, the system found that the outside air became clean at 790 sec. temporarily, but the sensor found that outside air had become polluted before it evacuated the polluted air within the reservoir completely. So the system closed the damper again. The pollution level was very high at this point and signal exceeded the fuil scale of the monitoring system. The contamination level would be of the order of $100 \mathrm{ppm}$ if the major component is $\mathrm{CO}$, or of the order of $10 \mathrm{ppm}$ if the major components is HCs. Similar data taken on the same rout on previous occasion was reported in Fig. 5 of Ref (3). The previous data was taken under more congested situation. It took $\sim 1700 \mathrm{sec}$. to drive the entire rout previously, but the corresponding time was $\sim 1200 \mathrm{sec}$. with the present data. However the level of pollution was somewhat higher in the present data despite the lighter traffic. The difference could be attributable to wind. The pollution level on the road is influenced by many factors, but wind and the degree of congestion could be two major decisive factors. Even a slight breeze of a few $\mathrm{m} / \mathrm{sec}$. would reduce the pollution by many folds.

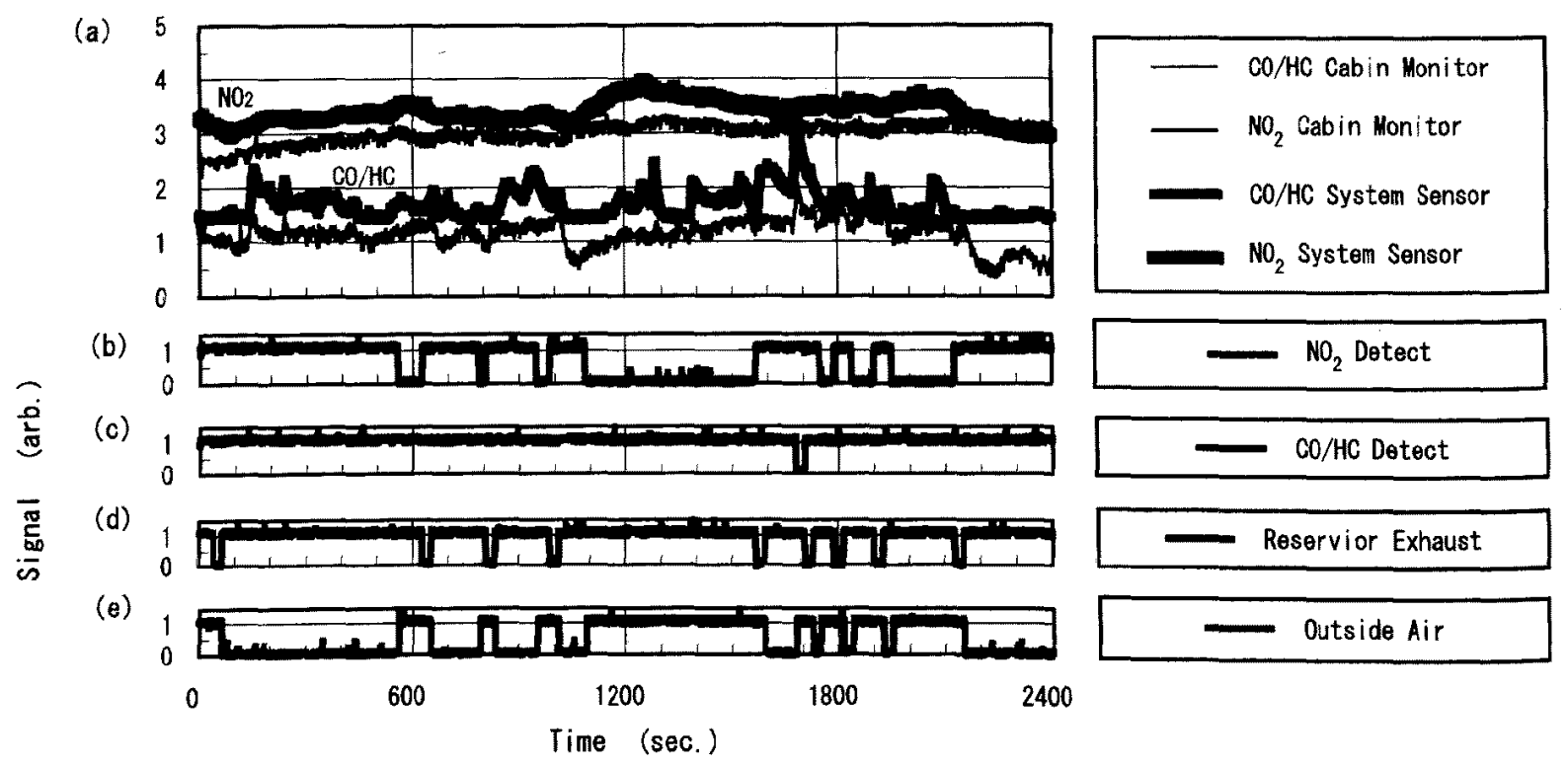

Fig. 5 Driving data of $\mathrm{NO}_{2}$ detection on a highway. 


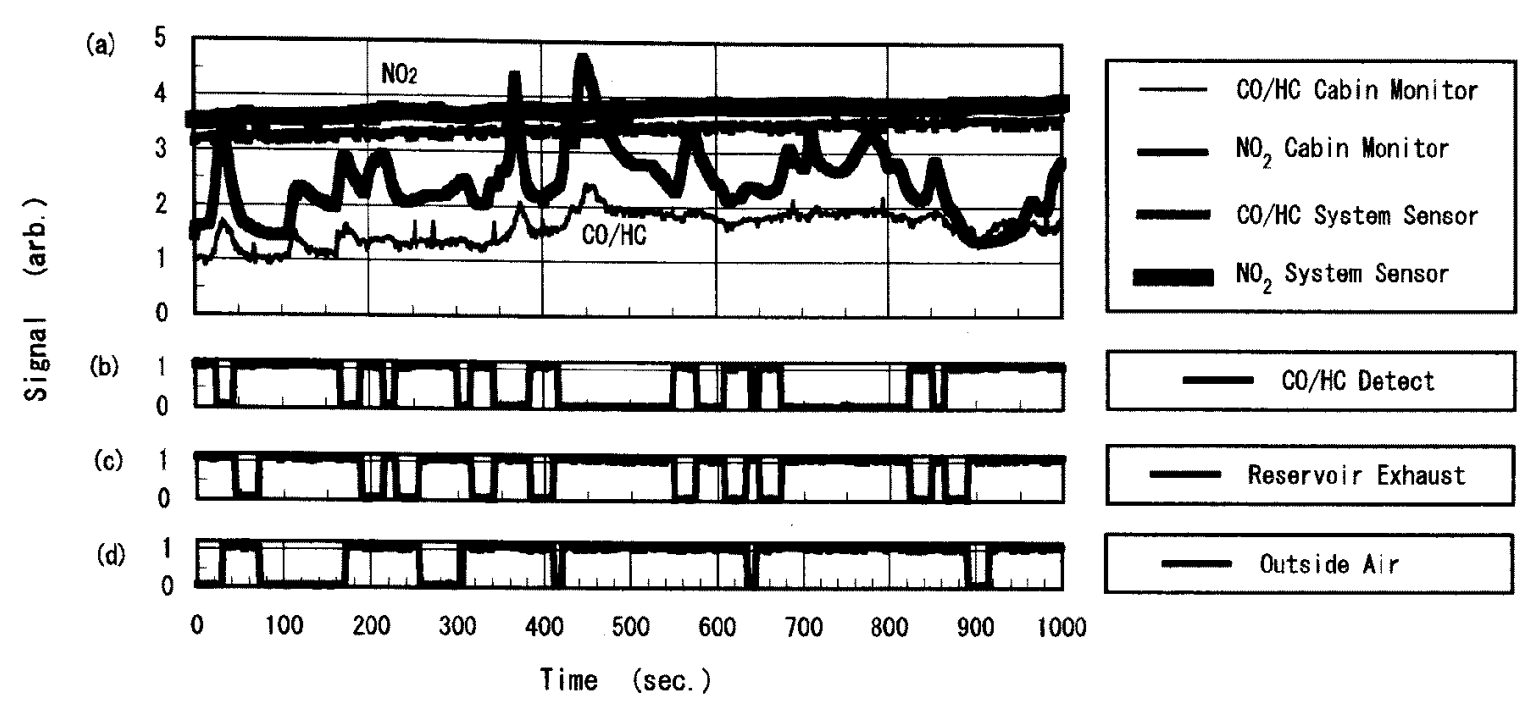

Fig. 6 Exhaust fime of a poorly tuned vehicle.

All the damper-closing actions presented in Fig. 4 were caused by the $\mathrm{CO} / \mathrm{HC}$ pollution. In fact the $\mathrm{CO} / \mathrm{HC}$ detector in most cases, more than $80 \%$ of the closing actions, detected the exhaust pollution. There were cases where $\mathrm{NO}_{2}$ detections dominated the pollution (Fig. 5). On this occasion, the traffic was heavy, but smooth. About $50 \%$ of the cars nearby were large freight tracks. In this case, the pollution level was relatively low despite the heavy traffic. It should be mentioned that even with the heavy traffic, the pollution level might not rise significantly as far as cars are running smoothly. But the pollution level becomes fierce when the traffic is congested. Although the pollution level of outside air was moderately high, the $\mathrm{CO} / \mathrm{HC}$ system sensor judged outside air to be polluted only once at $\sim 1700 \mathrm{sec}$ (Fig. 5 (c)). On the other hand, the signal from the $\mathrm{NO}_{2}$ system sensor showed $\mathrm{NO}_{2}$ contaminations, and the system judged several times that the outside air was polluted (Fig 5 (b)). The waveforms of $\mathrm{NO}_{2}$ sensors were quite different from those of $\mathrm{CO} / \mathrm{HC}$ sensors. The slow response, especially the fall time, was responsible for the difference, since both sensors were located in the same position. In this respect, it is desirable to have somewhat larger air reservoir to compensate the slow response of the $\mathrm{NO}_{2}$ sensor. However no passengers noticed the transient intake of the NOx polluted air, so far. As discussed previously, the $\mathrm{CO} / \mathrm{HC}$ sensor detected most polluted occasions. One could argue that the comfortable cabin climate may be achieved even with $1 \mathrm{CO} / \mathrm{HC}$ sensor, which is certainly cost-effective. But there were cases where the $\mathrm{NO}_{2}$. sensor detected the pollution despite the light emission of $\mathrm{CO} / \mathrm{HC}$ gases. Considering the fact that diesel exhaust contains highly cancer-stimulating materials, addition of the $\mathrm{NO}_{2}$ sensor would be a rational investment.

Figure 6 shows the road data with a poorly tuned car. It was late (about 11:30) at night, and the cars were scarce. Until $100 \mathrm{sec}$., the test car was driving behind several cars. But all the cars, except one small delivery van, made left-turn at $100 \mathrm{sec}$. Only the aforementioned delivery van was driving in front of the experimental car from 100 to $650 \mathrm{sec}$. It was clear that this car was responsible for the pollution during this period. Driving speed during this period ranged from 0 (The car stopped twice at red traffic signals during this period.) to $60 \mathrm{~km} / \mathrm{h}$. One could see the smoke come out from tail pipe when the driver accelerated despite the night road. Judging from the fact that $\mathrm{CO} / \mathrm{HC}$ signal was large and $\mathrm{NO}_{2}$ signal stayed calm, this car was likely to have some kind of malfunctioning or poor tuning which resulted in high fuel/air mix ratio. Abundance of experimental data indicated that both gasoline and diesel car emit relatively small amounts of harmful components, when they were properly tuned and properly driven ${ }^{(6)}$. It has been said that a small number of poorly tuned car contributed more than half of the traffic pollution ${ }^{(7)}$.

\section{Conclusion}

It has been proved that the ventilation system developed in the present research worked securely to cut out the unpleasant and harmful exhaust fume, while taking the clean fresh outside air. Similar systems had been on the market as an option for the highest-class passenger cars. Most of these systems utilize a single sensor to detect $\mathrm{CO}$ as an indicator for exhaust emission, which had been proved to have a risk of intake of NOx exhaust. Some systems utilized algorithms of introduction of outside air only when clean air persists for a certain period to avoid the transient intake of the polluted air caused by the slow sensor response, but these system may still have faulty intake of the polluted air when they entered to a polluted section from a clean area.

The requirement for the reservoir space would be the biggest 
shortcoming of the present system. Larger reservoir is necessary to have stronger air flow from ventilator. This requirement may be moderated by mixing the cabin air to fresh outside air at the air outlet.

Exhaust pollution is a complicated process and affected by many factors: traffic amount, traffic conditions (speed, degree of congestions, types and sizes of individual cars, tuned conditions of individual cars, driver's characteristics, etc.), geographical features, weather, and wind.

The data collected on the highway indicated that the worst pollution occurs when the traffic is congested with no wind. Even if the traffic is heavy, the pollution level may not rise so high if the traffic is moving smoothly or wind is breezing. Especially wind is the key determining factor and a wind velocity of more than a few $\mathrm{m} / \mathrm{sec}$ would reduce the pollution level significantly.

A car is a sword of twin edges in a modern life, and it is impossible to inhibit fossil-fuel cars in a day. But the present research indicated that the achievement for the smooth traffic and tight regulations for the poorly tuned cars would be a first step to be taken. The movement for a clean emission car and the reduction of car traffic to the polluted area would be an eventual step of course

The authors acknowledge New Cosmos CO. Ltd. and Figaro Engineering Co. Ltd. for the supply of sensors.

(Manuscript received February 28, 2000, revised October 30, 2000. )

\section{References}

(1) K. Oto, T. Nakahara, and I. Aso, Environmental gas sensor: an automatic ventilation system, T. IEE. Japan, 118-E,68(1998).

(2) G.M. Green et al., Diesel exhaust: A critical analysis of emission, exposure, and health effects, Health effect institute, Cambridge 1995.

(3) H. Nakagawa, S. Okazaki, S. Asakura, K. Fukuda, H. Akimoto, S. Takahashi, T. Shigemori, An automated car ventilation system, Sensors and Actuators B Chemical, B65, 133(2000).

(4) K. Ingrisch, A. Zeppenfeld, M. Bauer, B. Ziegenbein, H. Holland, and $\mathrm{B}$. Schumann, Chemical sensors for CO/NOx-Detection in automatic climate control system, SAE. Trans. 105, 900(1997).

(5) K. Oto, H. H. Kawahara, T. Manabe, T. Nomura, Y. Matsuura, and I. Aso, Dual-type sensor for controlling ventilation of cabin in motor vehicle, Chemical Sensors, 12B, 81(1996).

(6) W.O. Siegel, T.J. Korniski, J.F.O. Richert, E. Chladek, J.E. Weir, and T.E. Jensen, A comparison of the emission from a vehicle in both normal and selected malfunctioning operating modes, in :Emission and Emission Control SP-1207 SAE publications 33(1996)

(7) S.H. Cadle and R.D.Stephens, Remote sensing of vehicle exhaust emission, Environ. Sci. Technol. 28, 258A(1994).
Hidemoto Nakagawa (Member) received his Appl. Sci. and Ph.D. degrees

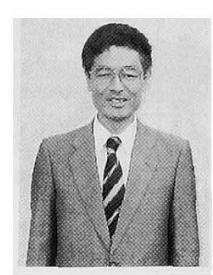
from the University of Toronto in 1974 and 1978, respectively. His research centers on various sensors and their applications, since he joined Yokohama National University in 1993. He is also working on micro- fabrication processes using chemical etching

Shinji Okazaki (Non-member) received his B.Eng. and M.Eng. degrees

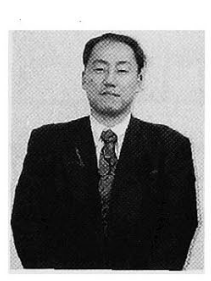
from the Yokohama National University in 1991 and 1993. He joined Yokohama National University as a research associate in 1997. His major fields are electrochemistry and sensor engineering.

Shukuji Asakura (Non-member) obtained his M.Eng. and Ph.D. degrees

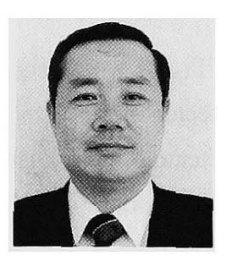
from the University of Tokyo in 1965 and 1968, respectively. In 1972, he joined Yokohama National University and became a full professor in 1988. His fields of interest are safety engneering, corrosion science and chemical sensors.

Hideo Akimoto (Non-member) obtained his B. Law from Chuo University

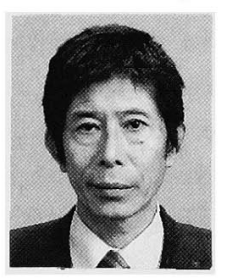
in 1971. He founded Advanced Circuit Engineering in 1988 and worked on designings and developments of various measurement systems.

Jun Kubo (Non-member) is the president of Kubo Systems. Inc. He

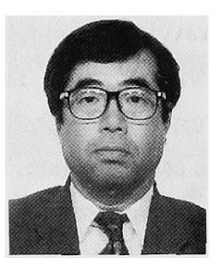
graduated Tokai Technical College in 1972. He is a specialist to build various automated systems using computers. 